\title{
1 Graphene-Based Nanostructured Materials for Advanced Electrochemical Water/Wastewater Treatment
}

\author{
Emmanuel Mousset ${ }^{1, \bowtie}$, Minghua Zhou ${ }^{2,3}$ \\ 1 Laboratoire Réactions et Génie des Procédés, UMR CNRS 7274, Université de Lorraine, 1 rue \\ Grandville BP 20451, 54001 Nancy cedex, France( $\triangle$ emmanuel.mousset@univ-lorraine.fr) \\ ${ }^{2}$ Key Laboratory of Pollution Process and Environmental Criteria, Ministry of Education, College of \\ Environmental Science and Engineering, Nankai University, Tianjin 300071, China \\ 3 Tianjin Key Laboratory of Urban Ecology Environmental Remediation and Pollution Control, College \\ of Environmental Science and Engineering, Nankai University, Tianjin 300071, China
}

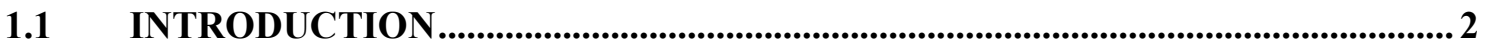

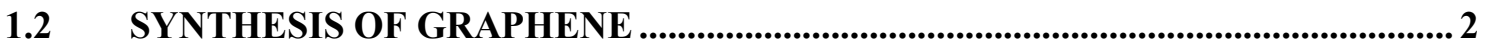

1.3 CHARACTERIZATION OF GRAPHENE ......................................................

1.4 MANUFACTURE OF GRAPHENE-BASED ELECTRODES ................................. 7

1.5 PROPERTIES OF GRAPHENE-BASED ELECTRODES ...................................9

1.6 WATER/WASTEWATER TREATMENT APPLICATIONS OF GRAPHENE-

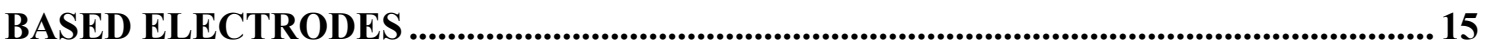

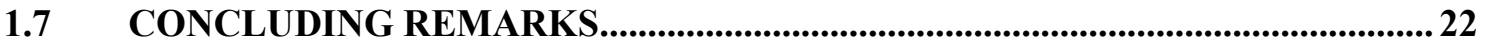

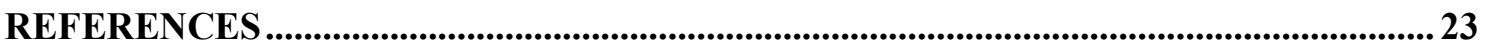

\begin{abstract}
The emerging development of graphene-based electrodes is critically reviewed. These promising materials have shown to enhance the electrochemical advanced oxidation processes (EAOPs) efficiency during wastewater treatment. Through thorough investigations, the main factors responsible of the success of such cathode in undivided electrolytic cell have been identified as follow: (i) carbonaceous raw material, (ii) nanostructured-coated materials, (iii) high-porosity materials, (iv) nitrogen-doped materials. These parameters participate to the enhancement of electroactive surface area and conductivity of electrode, two main material's properties that affect its efficiency. By combining all these characteristics, graphene-based electrode opens up new exciting EAOPs setups and should bring them closer to real applications.
\end{abstract}




\subsection{INTRODUCTION}

Nanomaterials have gained many interests in the two last decades and especially graphene that was discovered in $2004^{1}$ and drawn tremendous research attention due to its extraordinary properties such as high electron mobility (up to $200,000 \mathrm{~cm}^{2} \mathrm{~V}^{-1} \mathrm{~s}^{-1}$ ) , high thermal conductivity (up to $5,000 \mathrm{~W} \mathrm{~m}^{-1} \mathrm{~K}^{-1}$ ) , high mechanical strength (Young's modulus around $1.0 \mathrm{TPa}$ ), high optical transparency (up to $97.7 \%)^{5}$, large theoretical specific surface area $\left(2630 \mathrm{~m}^{2} \mathrm{~g}^{-1}\right)^{6}$ and many other promising characteristics. This ideal one-atom-thick fabric of $\mathrm{sp}^{2}$-hybridized carbon atoms arranged in a honeycomb structure is remarkably attractive for numerous applications that include energy generation and storage, sensors, composite materials, paints and coating, electronics and photonics. In recent past, the benefit from its large surface area was implemented in the treatment of water and wastewater such as heterogeneous photocatalysis, ${ }^{7}$ desalination $^{8}$ and adsorption ${ }^{9}$. Combined with an extremely high conductivity, graphene was more recently suggested to be used as an electrode material either in a galvanic mode (e.g. microbial fuel cells) ${ }^{10}$ or in an electrolytic cell (e.g. electrochemical advanced oxidation processes (EAOPs) $)^{11-17}$. The later technologies constitute a hot topic of research in water treatment area due to the clean reagent that is involve to produce extremely high oxidizing agents such as hydroxyl radicals $\left({ }^{\circ} \mathrm{OH}\right) .{ }^{18-22}$ Such processes are able to degrade and mineralize a wide range of organic load present in water even those containing persistent organic pollutants (POPs) that are bio-resistant.

In this context, the present chapter aims at giving a critical review of the research papers dealing with graphene-based electrodes employed in EAOPs processes by presenting the following consecutive steps as summarized in Fig. 1.1: (i) synthesis of graphene and its characterization, (ii) manufacture of graphene-based electrode and assessment of its properties, and (iii) its application in EAOPs for water/wastewater treatment.

\subsection{SYNTHESIS OF GRAPHENE}

There exist many production routes of graphene that can be grouped into either bottom-up or top-down approaches. ${ }^{23}$ Both of them have been used to produce graphene-based electrode for EAOPs application and they are described in the two following sections 1.2.1 and 1.2.2. 


\subsubsection{Bottom-Up Methods}

Bottom-up methods generate graphene by assembling small molecular building blocks into a single layer or a few layers of graphene. ${ }^{24}$ Among them, chemical vapor deposition (CVD) have been widely developed for the very high purity graphene production. ${ }^{25}$ It allows growing graphene either on Copper $(\mathrm{Cu})$ or Nickel $(\mathrm{Ni})$ substrates and then the graphene is transferred onto another substrate, depending on the application. The performance of CVD graphene in the form of graphene monolayer (Gmono), graphene multilayer (Gmulti) and three dimensional (3D) graphene foam (Gfoam) have been previously studied in EAOPs applications. ${ }^{13}$ To synthesize those graphene materials hydrogen and a carbon source (methane) gases were introduced into a furnace that heat at high temperature (around $1000^{\circ} \mathrm{C}$ ). The high thermal oxidation condition leads to methane decomposition in the presence of a transition-metal $(\mathrm{Cu}$ or $\mathrm{Ni}$ ) on which carbons atoms are deposited and rearranged into $\mathrm{sp}^{2}$-hybridized carbon structures. In the case of Gmono and Gmulti a thin copper film is used as a substrate ${ }^{26}$ while a $\mathrm{Cu}$ or $\mathrm{Ni}$ foam is employed to grow Gfoam. ${ }^{27}$ The Gmono is then transferred onto quartz material, ${ }^{26}$ while the metal skeleton is etched away in order to get graphene sheets (Gmulti) and a porous Gfoam structure $^{27}$. Large-scale CVD synthesis can be obtained using large substrates and large tube furnace according to the substrate-rolling synthesis strategy. ${ }^{28}$ For example, Gfoam area of 170 $\times 220 \mathrm{~mm}^{2}$ could be obtained with a furnace equipped with a quartz tube of $71 \mathrm{~mm}$ inner diameter. $^{27}$

However, the transfer process and metal removal usually causes significant degradation of the graphene quality due to the formation of wrinkles or structural damage from tearing and ripping. ${ }^{24}$ As a consequence, CVD graphene display poorer electronic and structural properties that the ideal one, ${ }^{29}$ which make competitive the top-down approach as presented thereafter (section 1.2.2).

\subsubsection{Top-Down Methods}

The top-down technique aims at weakening the van der Waals forces between the layers of graphite used as raw material in order to progressively obtain one single layer graphene. Two methods have been tested to produce graphene for EAOPs application: (i) the well-known and conventional Hummers method followed by reduction of graphene oxide $(\mathrm{GO})^{11,12,15-17,30}$ and (ii) the more recent electrochemical exfoliation technique ${ }^{14}$.

The first approach consists on applying strong chemical oxidation conditions $\left(\mathrm{KMnO}_{4}, \mathrm{NaNO}_{3}\right.$ and $\mathrm{H}_{2} \mathrm{SO}_{4}$ ) to get $\mathrm{GO}$ from exfoliated graphite. ${ }^{31}$ To avoid generation of toxic gas and to better control the temperature, a modified Hummers method has been proposed, namely Tour's 
method, by increasing the amount of $\mathrm{KMnO}_{4}$, excluding the use of $\mathrm{NaNO}_{3}$ and performing the reaction in a 9:1 mixture of $\mathrm{H}_{2} \mathrm{SO}_{4} / \mathrm{H}_{3} \mathrm{PO}_{4}{ }^{13,32}$ The $\mathrm{GO}$ is then reduced to get reduced graphene oxide (rGO). ${ }^{14,33}$

Alternatively, the electrochemical exfoliation method has been developed. It consists of applying a bias voltage (around $10 \mathrm{~V}$ ) between the cathode (graphite) and the anode (inert counter electrode such as platinum $(\mathrm{Pt})$ ) both immersed in a sulphated electrolyte (around 0.1 mol L-1). ${ }^{14,34-37} \mathrm{SO}_{4}{ }^{2-}$ ions can then be intercalated within graphite layer leading to its subsequent exfoliation. This method presents many advantages over the chemical method as it is faster with production rate of graphene that averaged $30.0 \mathrm{mg} \mathrm{h}^{-1}$ against $1.2 \mathrm{mg} \mathrm{h}^{-1}$ chemically. ${ }^{14,24}$ Secondly, it can be operated under ambient conditions while the chemical one need to heat at least at $50^{\circ} \mathrm{C}$, which further increase the energy requirements. Thirdly, it is more environmentally-friendly and safer, as it requires only power and a diluted electrolyte (0.01-1 mol L $\left.{ }^{-1}\right)$, whereas the rGO production method need highly-concentrated (0.3-20 mol L-1) acids, oxidizing agents and reducing agents. Additionally, it can be precisely tweaked by controlling the applied potential or current on the contrary to chemical approach.

Graphene need to be then characterized in order to further compare the efficiency of methods to produce graphene as discussed in section 1.3.

\subsection{CHARACTERIZATION OF GRAPHENE}

To investigate the characteristics of the graphene produced via CVD, chemical or electrochemical methods the surface morphology as well as structural and physico-chemical properties are commonly assessed.

\subsubsection{Surface Morphology}

The morphology (e.g. roughness, sheet size, number of sheets, interlayer distance, pore size) of graphene is commonly assessed by microscopy: (i) atomic force microscope (AFM), (ii) (high resolution) transmission electron microscope ((HR)TEM), and/or (iii) scanning electron microscope (SEM).

Examples of images depicting CVD Gmono, electrochemically-exfoliated graphene (EEG), CVD Gmulti and CVD Gfoam are shown in Fig. 1.2a, 1.2b, 1.2c and 1.2d, respectively. ${ }^{13,14}$ AFM results (Fig. 1.2a) show that the average roughness of CVD Gmono was $0.37 \mathrm{~nm}$, which is very close to $0.34 \mathrm{~nm}$ - the theoretical thickness of a single layer of graphene. ${ }^{13}$ The slight difference of $0.03 \mathrm{~nm}$ could be attributed to the presence of functional groups on the graphene surface (section 1.3.2). Comparatively, the roughness of GO produce by Hummers method was $1 \mathrm{~nm},{ }^{11}$ demonstrating the presence of numerous oxygen functional groups on the graphene 
surface (section 1.3.2). Regarding the CVD Gmulti, an average roughness of $227 \mathrm{~nm}$, highlighted an average number of layer around 667.

In Fig. 1.2b (left), an EEG sheet was distinctly identified with a size around $7.5 \mu \mathrm{m}$, in the range of EEG sheet $(5-10 \mu \mathrm{m})$ obtained by statistical analysis ${ }^{34,37}$. A micrograph on the edge of the sheet (Fig. 1.2b (right)) highlight the number of layers (5) with an interlayer distance of $0.4 \mathrm{~nm}$ ( $2 \mathrm{~nm}$ thickness in total). Considering the theoretical interlayer distance of $0.34 \mathrm{~nm}$, the $0.06 \mathrm{~nm}$ difference could be attributed to the few oxygen-containing groups on the graphene surface ${ }^{14,35}$, as discussed in section 1.3.2. Still, the high degree of transparency in TEM micrographs of single or few graphene sheets made by CVD, electrochemical or chemical method indicated the very low thickness of this nanomaterial. ${ }^{13,15,30}$

SEM picture in Fig. 1.2c displayed the flat surface of Gmulti and numerous graphene sheets less ordered than in graphite material (section 3.1.2). ${ }^{13}$ Contrastingly, the 3D Gfoam (Fig. 1.2d) clearly showed large open pores (100 to $600 \mu \mathrm{m})$ that are expected to increase the surface area and facilitate molecule diffusion inside the pores. ${ }^{13}$

Further analyses are usually performed to better assessed the quality of produced graphene as after-mentioned in section 1.3.2.

\subsubsection{Purity and Structural Properties}

Spectroscopy techniques such as X-ray diffraction (XRD), Fourier transform infrared (FTIR) and Raman as well as photoelectron spectroscopy (XPS) have been commonly used to assess the crystalline structure (By XRD), the functional groups (By FTIR, Raman and XPS) and the surface elemental composition (by XPS) of graphene materials. ${ }^{11,13-15,17,30}$

XRD patterns of Gmono, Gmulti and Gfoam produced by CVD method are displayed in Fig. 1.3a. A string and sharp diffraction peak (002) at $2 \theta=26.5^{\circ}$ and a weaker sharp peak (004) at $2 \theta=54.6^{\circ}$ were observed for all CVD graphene materials. Those peaks could be ascribed to the crystalline graphitic structure. ${ }^{13,38}$ It revealed the high crystalline degree of Gmono and Gmulti while background noise in Gfoam patterns could be attributed to amorphous characteristics and lesser-ordered structure. ${ }^{13}$ On the contrary, XRD of GO does not exhibited a peak at $26^{\circ}$ whereas a reflection at $12.5^{\circ 11}$ was noticed confirming the high degree of oxidation and certifying that all the raw graphite was converted into GO. ${ }^{11}$ The reflection of a peak at $47.8^{\circ}$ exhibited the hexagonal phase (012) of GO. ${ }^{30}$

Raman spectra of graphene materials usually display 3 kinds of peaks, namely (i) the D peak at around $1350 \mathrm{~cm}^{-1}$ that represents the number of defects, (ii) the $\mathrm{G}$ peak at around $1580 \mathrm{~cm}^{-1}$ that is relevant to the $\mathrm{sp}^{2}$-hybridized carbon-carbon bonds in graphene and (iii) the $2 \mathrm{D}$ peak at 
around $2690 \mathrm{~cm}^{-1}$ that provides information on the stacking order. ${ }^{39,40}$ Two main ratio have employed as indicator in order to assess and compare the quality of graphene, i.e. the intensity of D peak (I(D)) over the intensity of $G$ peak $(I(G))(I(D) / I(G))$ that expresses the number of defects and $\mathrm{I}(\mathrm{D})$ over the intensity of $2 \mathrm{D}$ peak (I(2D)) (I(2D)/I(G)) that exemplifies the graphitization degree for $\mathrm{C}=\mathrm{C} \mathrm{sp}{ }^{2}$ bonds in graphitic carbons. Both ratio have been plotted in Fig. $1.3 \mathrm{~b}$ and allows comparing the $\mathrm{GO}^{15,30}, \mathrm{EEG}^{14}$ and $\mathrm{CVD}$ productions of Gmono, Gmulti and Gfoam ${ }^{13}$. I(D)/I(G) ratio of EEG was lower (0.68) than for GO (0.90). Knowing that the lower $\mathrm{I}(\mathrm{D}) / \mathrm{I}(\mathrm{G})$ ratio the lower the defects, it shows that EEG had less number of defects than GO. It could be accredited to the oxygen-functional groups of GO. Regarding the I(2D)/I(G) ratio values, they were ranked as follow: CVD Gmono (3.66) > CVD Gfoam (1.58) > CVD Gmulti (0.97) > EEG (0.92) > Graphite (0.59). CVD provided higher quality of $\mathrm{C}=\mathrm{C}$ bond recovery when the number of layer decreases. ${ }^{13,36}$ In addition, the ratio value of Gfoam $(3.66)^{13}$ was close to the theoretical one $(4)^{40}$. Graphite had the lower quality while ratio value of EEG was close to CVD Gmulti. ${ }^{13,14}$

To further determine the surface elements and functional groups that could be present on graphene materials, XPS analyses are traditionally performed. $\mathrm{C} 1 \mathrm{~s}$ deconvolution graphs allows indentifying and qualifiying $\mathrm{C}=\mathrm{C} / \mathrm{C}-\mathrm{C} / \mathrm{C}-\mathrm{H}$ bonds present in aromatic rings (peak at $284.5 \mathrm{eV}$ ), epoxy and alkoxy bonds $(\mathrm{C}-\mathrm{O})$ (peak at $286 \mathrm{eV}$ ), $\mathrm{C}=\mathrm{O}$ bond (peak at $287.5 \mathrm{eV}$ ) and $\mathrm{O}-\mathrm{C}=\mathrm{O}$ (peak at $289 \mathrm{eV}$ ) functional group. ${ }^{13,33}$ The $\mathrm{sp}^{2}$ carbons were presents in majority in all graphene materials whatever the production method. ${ }^{11,13,15}$ Oxygen-containing group such as $\mathrm{C}-\mathrm{O}$ was still distinguished in CVD graphene materials, $\mathrm{GO}$ and $\mathrm{rGO} \cdot{ }^{11,13,15} \mathrm{C}=\mathrm{O}$ and $\mathrm{O}-\mathrm{C}=\mathrm{O}$ functional groups were found in a lesser extent in GO and rGO materials. ${ }^{11,15}$ The presence of oxygen in the graphene material is further assessed by the carbon atomic percentage over oxygen atomic percentage $(\mathrm{C} / \mathrm{O})$ ratio. The higher the $\mathrm{C} / \mathrm{O}$ ratio the higher the quality of graphene. $\mathrm{C} / \mathrm{O}$ ratio of $\mathrm{GO}^{11}, \mathrm{CVD}$ graphene ${ }^{13}$ and graphite ${ }^{13}$ have been compared in Fig. 1.3c and ranked as follow: CVD Gmono (32) > CVD Gmulti (25) > CVD Gfoam (22) > graphite (19) > GO (2.75). First, it can be considered that graphite was completely converted into $\mathrm{GO}$ since the $\mathrm{C} / \mathrm{O}$ ratio was higher than 2.0. ${ }^{41}$ Second, it again emphasized the higher quality of graphene obtained with CVD technique. Few oxygen atoms remained in CVD Gmono which corroborated the difference of thickness $(0.37 \mathrm{~nm})$ with the theoretical value $(0.34 \mathrm{~nm})$ (section 1.3.1).

\subsubsection{Sheet resistance}

The quality of graphene can be further assessed by sheet resistance measurements usually expressed in ohm per square $\left(\Omega \square^{-1}\right)$. Two- or preferentially four-point probe devices connected 
to a multimeter are commonly used to quantify the sheet resistance of graphene sheets. ${ }^{42}$ The electrically exfoliated graphene was compared to a modified Hummer's method (Tours technique) to produce graphene. A 6-fold higher sheet resistance was noticed with the chemical method (30 $\Omega \square^{-1}$ ) against the electrochemical (5.1 $\Omega \square^{-1}$ ). The typical range of rGO (14-52 $\Omega$ $\left.\square^{-1}\right)^{43}$ made it less conductive than the EEG. Knowing that CVD method could reached a sheet resistance as low as $4.4 \Omega \square^{-1}$ for a single layer graphene, the electrochemical exfoliation method opens up an environmentally-friendly alternative to produce graphene. ${ }^{14}$

\subsection{MANUFACTURE OF GRAPHENE-BASED ELECTRODES}

Once the graphene is synthesized and characterized, it is either tested as an electrode itself $(\text { CVD Gmono, Gmulti and Gfoam) })^{13}$ or it is transferred onto a raw conductive material ${ }^{11,12,14-}$ ${ }^{17,30}$, which is the subject of this section 1.4. Several transfer techniques have been proposed and they have been categorized into two ways of electrode manufacturing: (i) methods requiring the use of binder, (ii) methods without binder requirement.

\subsubsection{Manufacturing Methods Using Binder}

Most of the studies developed methods requiring the use of additional binder to coat the graphene on raw conductive material in order to be used in EAOPs applications (Table 1.1). Three binding agents have been employed: (i) polytetrafluoroethylene (PTFE) ${ }^{15,16}$, (ii) Nafion $^{14,30}$ and (iii) polypyrrole ${ }^{17}$. Those polymers have good electrochemical stability and they are not electroactive in the range of potentials applied in EAOPs. ${ }^{14,44-46} \mathrm{In}$ addition, it has been laid out that PTFE deliver two functions in the electrode material namely to bind the high surface graphene onto a cohesive layer and to impart some hydrophobic characteristics. ${ }^{14,15,47}$ Moreover, Nafion is an ionomer consisting of hydrophobic fluoro-backbone and a hydrophilic sulfonic acid group Nafion can strongly be adsorbed onto graphene surface by hydrophobic interactions followed by steric and increased electrostatic repulsions between graphene sheets by inducing a negative charge on the graphene surface. Both repulsive reactions allowed overcoming the van der Waals force between the graphene sheet. Therefore, the amphiphilic property of Nafion favor graphene dispersion and stabilization in solution. Nafion also acts as interfacial binder and favor the hydrophobic interactions between the graphene dispersions and the raw material. Moreover, the sole presence of Nafion caused a slight improvement in electrocatalytic activity, ${ }^{14}$ which could be ascribed to its electrical conductivity that could possibly increase the electrochemical rate of reactions occurring at the surface of the electrode. ${ }^{48}$ 
The concentration of interfacial binder as well as the binder/graphene ratio play a major role in the electrocatalytic efficiency of electrode. An increase of hydrophobic binder (e.g. PTFE) has shown to minimize the cathode flooding and facilitating gas distribution and subsequent electrochemical reaction such as $\mathrm{O}_{2}$ reduction into $\mathrm{H}_{2} \mathrm{O}_{2} \cdot{ }^{47}$ However, an excess of binder (e.g. Nafion) has demonstrated to reduce the porosity and the available surface area. ${ }^{14,45}$ Similarly, an increase of graphene concentration exposed a raise of catalytic activity by increasing the specific surface area and the electrical conductivity until a maximal graphene concentration. ${ }^{14}$ At such high amount, graphene starts aggregating due to insufficient quantity of dispersant, which decrease surface area and porosity of the electrode material. ${ }^{14}$ After varying the concentrations of Nafion and graphene, a Nafion to graphene ratio of 1:4 (w/w) was found optimal when coated on carbon cloth $^{14}$, while an optimal graphite/graphene/PTFE ratio was determined to be 8:1:2 when stuck on stainless steel mesh. ${ }^{16}$

The graphene loading achieved by the mass transfer of graphene to the raw material is another important parameter to determine. It allows getting accurate binder to graphene mass ratio and normalizing the amount of graphene to the surface of the raw material employed. Though, this is fundamental to allow comparing graphene cathodes, most papers do not report the graphene loading except Mousset et al. ${ }^{14}$ who calculated the weight of graphene transferred to the cloth. The average graphene loading equaled $0.27 \mathrm{mg} \mathrm{cm}^{-2}$ at optimal Nafion and graphene concentrations. ${ }^{14}$

The nature of raw materials employed as current collector is further capital. Two kinds of primary materials have been applied, e.g. stainless steel mesh ${ }^{15-17}$ and carbon materials (glassy carbon $^{30}$ and carbon cloth $^{14}$ ). Carbonaceous materials are usually preferred for EAOPs applications as it catalyzes the $\mathrm{H}_{2} \mathrm{O}_{2}$ electrogeneration by having (i) high $\mathrm{H}_{2}$ evolution overpotential, (ii) low catalytic activity for $\mathrm{H}_{2} \mathrm{O}_{2}$ decomposition, (iii) good conductivity, (iv) high chemical resistance and (v) by being non-toxic for water/wastewater applications. ${ }^{18}$

Following the wake of graphene, recent applications have been devoted to the assembly of 2D materials. ${ }^{49} \mathrm{~A} 3 \mathrm{D}$ carbon-network has been developed with alternate connections of aligned carbon nanotubes (CNTs) and rGO nanosheets (rGO@CNT) doped with nitrogen (NrGO@CNT) to get advanced multifunctional structures. ${ }^{15}$ Such carbonaceous material has been employed as cathode in EAOPs application. ${ }^{15}$

Though, binder properties have shown to be positive in the graphene-based electrode manufacture, some authors suggested alternative method to produce electrode without the need of binders. Such techniques are presented hereafter. 


\subsubsection{Binder-Free Manufacturing Techniques}

Some authors ${ }^{12,50,51}$ assume that the presence of binder hinder the properties of graphene, which result in lower conductivity of the composite and lower graphene loading. It also requires the addition of chemicals, which makes the method less simple. ${ }^{51}$ Le et al. ${ }^{12,50}$ suggested an electrophoretic deposition of GO $\left(1.5 \mathrm{mg} \mathrm{mL}^{-1}\right)$ - produced by modified Hummers method followed by its electrochemical reduction to form $\mathrm{rGO}$ on a raw material (e.g. carbon felt (CF)). ${ }^{50}$ The essential parameters affecting the modification such as current density value, time of GO deposition on the substrate and conditions of electrochemical reduction were investigated. Finally, a current density of $-1.5 \mathrm{~mA} \mathrm{~cm} \mathrm{~cm}^{-2}$ for $10 \mathrm{~min}$ of electrolysis were determined to be optimal. ${ }^{50}$ Furthermore, GO could serve as weak supporting electrolyte as it is conductive, meaning that sodium sulfate or potassium chloride were not necessary to add in the solution. ${ }^{50}$ The constant potential reduction of GO on CF raw material (CPrGO-CF) method was compared to the chemical reduction technique (CrGO-CF) by adding a mixture of hydrazine (35 $\mathrm{wt} \%$ ) and ammonia (28 wt \%) and the thermal reduction (TrGO-CF) approach by pyrolizing at $1000^{\circ} \mathrm{C}$ for 1 h. ${ }^{12}$

Upon all these techniques implemented to manufacture graphene-based electrodes, their properties need to be established in order to compare the different approaches as discussed in section 1.5 .

\subsection{PROPERTIES OF GRAPHENE-BASED ELECTRODES}

The manufactured graphene-based electrode can be characterized according to their (i) surface morphology, (ii) wettability, (iii) electrical conductivity, (iv) electroactive surface area and (v) oxygen reduction reaction (ORR) activity.

\subsubsection{Surface Morphology}

To investigate the coating efficiency of the graphene on primary materials, SEM analyzes are first conducted as a qualitative approach. ${ }^{11,12,14,16,17}$ Samples of images ${ }^{14}$ are displayed in Fig. 1.4. From the micrographs obtained at $\times 1000$ magnification (Fig. 1.4a), it is shown that carbon cloth consisted of an entwined network of carbon microfilaments with an average diameter of $10 \mu \mathrm{m} .{ }^{14}$ It is further illustrated that the fibers of the uncoated cloth (left) were clean whereas the fibers of graphene-coated cloth (right) displayed microscale clusters of graphene sheets intertwined in the carbon network, indicating successful transfer onto the primary material. ${ }^{14}$ At $\times 5000$ (Fig. 1.4b) magnification, the image on the left revealed the uniform and smooth surface 
whereas details of the graphene clusters (right) ranging from 1-20 $\mu \mathrm{m}$ in length appended on the cloth. A feature confirmed by Le et al. ${ }^{12}$ and Zhao et al. ${ }^{17}$ studies. The reduction treatment of GO impacted on the surface morphology as well. Though raw CF had a soft surface, the chemical reduction makes increase the number of pores and clusters of graphene deposited on CF. ${ }^{12}$ The electrochemical and thermal reduction of GO could even higher the amount of asperity. ${ }^{12}$

The polished surface of the uncoated material is expected to lower surface area while the rough surface forecast an increase of the area as further noticed. ${ }^{12,14,17}$ This particularity would impact on the electrocatalytic activity of the electrode material as further discussed.

\subsubsection{Wettability}

The hydrophilicity/hydrophobicity of electrode material is an important criterion that has shown to have double contradictory effects in literature: (i) a high hydrophilicity could improve dissolved $\mathrm{O}_{2}$ diffusion and adsorption at the cathode surface and can then be easily reduced into $\mathrm{H}_{2} \mathrm{O}_{2}$ (Eq. 1.1), ${ }^{12}$ while (ii) a high hydrophobicity could favor the $\mathrm{O}_{2}$ gas absorption on the cathode material before being reduced into $\mathrm{H}_{2} \mathrm{O}_{2}$ (Eq. 1.1) ${ }^{47}$. Both mechanisms lead to the generation of ${ }^{\circ} \mathrm{OH}$ through Fenton reaction (Eq. 1.2).

$$
\begin{aligned}
& \mathrm{O}_{2}+2 \mathrm{H}^{+}+2 \mathrm{e}^{-} \rightarrow \mathrm{H}_{2} \mathrm{O}_{2} \\
& \mathrm{H}_{2} \mathrm{O}_{2}+\mathrm{Fe}^{2+} \rightarrow \mathrm{OH}^{\circ}+\mathrm{Fe}^{3+}+\mathrm{HO}^{-}
\end{aligned}
$$

To assess the hydrophilicity/hydrophobicity on the surface of graphene-based electrode materials contact angles measurements of water droplets have been performed. ${ }^{12,13}$ Figure 1.5 depicts contact angles measurement done with CVD Gmono, CVD Gmulti and CVD Gfoam materials. ${ }^{13}$ The carbon materials were ranked as follows, from the least hydrophobic: Gfoam $\left(128.3^{\circ}\right)>$ Gmulti $\left(87.1^{\circ}\right)>$ Gmono $\left(82.6^{\circ}\right)$. It is clearly discerned that the more layers of graphene, the more hydrophobicity of graphene, which corroborates the increasing apolar aromatic rings. ${ }^{13,52}$ Contact angles measurements have been also performed with uncoated $\mathrm{CF}$ and graphene-coated CF (CrGO-CF, CPrGO-CF and TrGO-CF) ${ }^{12}$ as displayed in Fig. 1.6a. It is obvious that the reduction method affected the hydrophilicity of the material in the following (from the least hydrophobic): $\mathrm{CF}\left(89.9^{\circ}\right)>\mathrm{CrGO}-\mathrm{CF}\left(68.3^{\circ}\right)>\mathrm{CPrGO}-\mathrm{CF}\left(41.8^{\circ}\right)>\mathrm{TrGO}-\mathrm{CF}$ $(\sim 0)$. The water droplets adsorbed immediately after contact with TrGO-CF material. The thermal reduction affected more the raw material by bringing lot of open pores - as inspected on SEM pictures - that helped the quick water adsorption. ${ }^{12}$ The same phenomenon could also occur with the two other reduction methods (e.g. chemical and electrochemical) but in a lesser 
extent. It is also interesting to note that CF-based materials were more hydrophilic than the CVD graphene electrodes. It could be attributed to the higher oxygen content in $\mathrm{CrGO}-\mathrm{CF}(\mathrm{C} / \mathrm{O}$ $=4.66)^{12}, \mathrm{CPrGO}-\mathrm{CF}(\mathrm{C} / \mathrm{O}=7.72)^{12}$ and TrGO-CF $(\mathrm{C} / \mathrm{O}=15.39)^{12}$ than in CVD graphenes $(\mathrm{C} / \mathrm{O} \text { ranging from } 22 \text { to } 32)^{13}$. It means that the numerous oxygen functional groups in rGOcoated $\mathrm{CF}$ participated to increase the polarity of the material as compared to the non-polar $\mathrm{sp}^{2}$ carbon of pristine graphene.

\subsubsection{Electrical Conductivity}

The electrical conductivity of electrode material is an important parameter as it plays roles (i) in the kinetics of electrochemical reaction occurring at electrode surface and (ii) on the energy consumption by reducing the cell potential. Electrochemical impedance spectroscopy (EIS) is an efficient tool for studying the interface properties and electron transfer mobility between the electroactive substance and the electrode material. EIS has been used to assess the electrical conductivity of the graphene-based electrode by using a three-electrode system connected to a potentiostat, in which an electroactive specie $\left(\mathrm{K}_{3}\left[\mathrm{Fe}(\mathrm{CN})_{6}\right]\right)$ - sensitive to the surface chemistry of carbon-based electrodes - and an inert support electrolyte $(\mathrm{KCl})$ are added in aqueous solution. ${ }^{12-14}$ The impedance spectra can be then recorded at open circuit voltage (OCV) with frequency ranging from $50 \mathrm{kHz}$ to $100 \mathrm{mHz}$ and a voltage amplitude of $10 \mathrm{mV} \cdot{ }^{12-14}$ The Nyquist plot allows then determining the interfacial charge transfer resistance $\left(\mathrm{R}_{\mathrm{ct}}\right)$ of the material that corresponds to the intercept of the semicircle with the real axis (X-axis). ${ }^{12-14}$

$\mathrm{R}_{\mathrm{ct}}$ values of pristine CVD graphene materials have been represented in Fig. 1.6b and ranked as follow: Gmono $(\sim 3600 \Omega)>$ Gmulti $(123 \Omega)>$ Gfoam $(1.6 \Omega)$. A significant increase of electrode conductivity was noticed with the increase of graphene thickness as reported by further authors. ${ }^{13,53}$ The graphene layers in Gfoam are randomly assembled, unlike the ordered stacking observed with graphite. ${ }^{53}$ The arbitrary stacking decouples the adjacent graphene sheets so that the electronic property of each layer is similar to that of single graphene.${ }^{54}$ Consequently, the overall resistivity of multi-layer graphene decreases with the number of graphene sheets. ${ }^{53,54}$ This is further consistent with the lower conductivity of graphite ( $92 \Omega$ ) as compared to Gfoam $(1.6 \Omega)$. Interestingly, the conductivity of CVD Gfoam was slightly higher than CF, whose $\mathrm{R}_{\mathrm{ct}}$ value equaled $2.4 \Omega^{12}$ as shown in Fig. 1.6b. CF had larger number of defects caused by the presence of oxygen functional group that alter the electrical conductivity. ${ }^{13,43}$ Since the high conductivity of pristine graphene rely on its $\mathrm{sp}^{2}$-hybridized honeycomb structure the presence of oxygen functional groups disrupt its structure and localize $\pi$-electrons which therefore 
decreased their mobility, i.e. decreased the conductivity of rGO compared to pristine graphene. ${ }^{43}$

Moreover, the reduction method further improved the conductivity of raw $\mathrm{CF}$ with $\mathrm{R}_{\mathrm{ct}}$ values decreasing from $0.5 \Omega$ (CrGO-CF) to around $0.21 \Omega$ (CPrGO-CF and TrGO-CF). This was in agreement with the increasing $\mathrm{C} / \mathrm{O}$ values from raw $\mathrm{CF}$ to $\mathrm{TrGO}-\mathrm{CF}$ as mentioned in sections 1.5.2. Furthermore, the presence of EEG on carbon cloth could reduce the $R_{c t}$ from $81.1 \Omega$ (raw cloth) to $2.45 \Omega$, a 33-fold improvement (Fig. 1.6b). ${ }^{14}$ Contrastingly, a 3-times lower enhancement of CPrGO-CF against raw CF was noticed. This could be accounted for the use of rGO which was reported to contain defects related to oxygen functionalities that could reduce its electrical conductivity. ${ }^{13,43}$

\subsubsection{Electroactive Surface Area}

The electroactive surface area is a key point in advanced electrocatalysis as it increases the number of active site for molecule reduction. This is the case of $\mathrm{O}_{2}$ adsorption on the carbon cathode surface before its subsequent reduction into $\mathrm{H}_{2} \mathrm{O}_{2}$, the adsorption stage being the limiting step according to the following reaction sequence (Eqs. 1.3a-3e) that is equivalent to the global Eq. 1.1: $:^{55,56}$

$$
\begin{aligned}
& \mathrm{O}_{2} \quad \rightarrow \quad \mathrm{O}_{2(\mathrm{ads})} \\
& \mathrm{O}_{2(\mathrm{ads})}+\mathrm{e}^{-} \quad \rightarrow \quad \mathrm{O}_{2}{ }^{-{ }^{-}(\mathrm{ads})} \\
& \mathrm{O}_{2}{ }^{\cdot-}{ }_{(\text {ads })}+\mathrm{H}^{+} \quad \rightarrow \quad \mathrm{HO}_{2}{ }_{(\mathrm{ads})} \\
& \mathrm{HO}_{2}{ }^{\circ}{ }^{(\mathrm{dds})}+\mathrm{e}^{-} \rightarrow \mathrm{HO}_{2}{ }^{-} \\
& \mathrm{HO}_{2}{ }^{-}+\mathrm{H}^{+} \quad \rightarrow \quad \mathrm{H}_{2} \mathrm{O}_{2}
\end{aligned}
$$

Electroactive surface area of carbon materials can be obtained from cyclic voltammetry $(\mathrm{CV})$ of $\left[\mathrm{Fe}(\mathrm{CN})_{6}\right]^{3-} /\left[\mathrm{Fe}(\mathrm{CN})_{6}\right]^{4-}$ reversible redox couple in which the anodic peak current value $\left(I_{\mathrm{p}}\right.$ in $\left.\mathrm{A}\right)$ of the cycle is used to calculate the surface $\left(A\right.$ in $\left.\mathrm{cm}^{2}\right)$ according to Randles-Sevcik equation (Eq. 1.4): $:^{12-14,57,58}$

$I_{p}=2.69 \times 10^{5} \times A D^{1 / 2} n^{1 / 2} \gamma^{1 / 2} C$

where $n$ is the number of electrons participating in the redox reaction $(\mathrm{n}=1), D$ is the diffusion coefficient of the molecule in solution $\left(7.60 \times 10^{-6} \mathrm{~cm}^{2} \mathrm{~s}^{-1}\right.$ for $\left[\mathrm{Fe}(\mathrm{CN})_{6}\right]^{3+} /\left[\mathrm{Fe}(\mathrm{CN})_{6}\right]^{4-}$ redox couple), $C$ is the concentration of the probe molecule in the bulk solution ( $\mathrm{mol} \mathrm{cm} \mathrm{cm}^{-3}$ ), and $\gamma$ is the scan rate of the potential perturbation $\left(\mathrm{V} \mathrm{s}^{-1}\right)$. 
Generally, the applied potential is ranging from -0.4 to $0.8 \mathrm{~V} \mathrm{vs} \mathrm{Ag} / \mathrm{AgCl}$ at a scan rate of 10 $\mathrm{mV} \mathrm{s}^{-1} \cdot{ }^{12-14}$ From Randles-Sevcik equation it can be deduced that the higher $I_{\mathrm{p}}$, the higher electroactive surface area. Electroactive surface area of different graphene-based electrode materials have been calculated and displayed in Fig. 1.6c. CVD graphene materials could be ranked as follow: Gmono $\left(0.015 \mathrm{~cm}^{2}\right)<$ Gmulti $\left(4.99 \mathrm{~cm}^{2}\right)<$ Gfoam $\left(55.02 \mathrm{~cm}^{2}\right)$. Gfoam acquired higher surface area, which could be due to its 3D porous structure, as observed by SEM (section 1.3.1). ${ }^{13}$ CF-based electrodes were ranked as follow: raw CF $\left(13.80 \mathrm{~cm}^{2}\right)<$ CrGO-CF $\left(27.59 \mathrm{~cm}^{2}\right)<$ TrGO-CF $\left(124.17 \mathrm{~cm}^{2}\right)<$ CPrGO-CF $\left(137.97 \mathrm{~cm}^{2}\right) .{ }^{12}$ Again, thermal and electrochemical reduction of GO make increase the surface area higher, with an improvement ranging from 9 to 10 times as compared to the uncoated $\mathrm{CF}$, which is in accordance with SEM pictures (section 1.5.1). A 11.5-fold enhancement could be further noticed between EEG-Cloth $\left(6.31 \mathrm{~cm}^{2}\right)$ and the raw cloth $\left(0.57 \mathrm{~cm}^{2}\right)$. This is slightly higher gain of surface as compared to CPrGO-CF with CF.

In order to better compared the materials, it has been previously suggested to normalized the electroactive surface area either by the geometric surface of $2 \mathrm{D}$ electrodes or the volume of electrode for 3D materials. ${ }^{13}$ The results are shown in Fig. 1.6c. The following rank was noticed for 2D materials: CVD Gmono $\left(0.0024 \mathrm{~cm}^{2} \mathrm{~cm}^{-2}\right)<$ cloth $\left(0.024 \mathrm{~cm}^{2} \mathrm{~cm}^{-2}\right)<$ CVD Gmulti $\left(0.125 \mathrm{~cm}^{2} \mathrm{~cm}^{-2}\right)<$ EEG-Cloth $\left(0.26 \mathrm{~cm}^{2} \mathrm{~cm}^{-2}\right),{ }^{13,14}$ while for 3D materials it was ordered as follow: CVD Gfoam $\approx \mathrm{CF}\left(27.5 \mathrm{~cm}^{2} \mathrm{~cm}^{-3}\right)<\mathrm{CrGO}-\mathrm{CF}\left(55.2 \mathrm{~cm}^{2} \mathrm{~cm}^{-3}\right)<\operatorname{TrGO}-\mathrm{CF}\left(248 \mathrm{~cm}^{2}\right.$ $\left.\mathrm{cm}^{-3}\right)<$ CPrGO-CF $\left(276 \mathrm{~cm}^{2} \mathrm{~cm}^{-3}\right)^{12,13}$. EEG-Cloth and CPrGO-CF accounted for the best existing graphene-based 2D and 3D materials respectively, in terms of electroactive surface area. It is still important to note that porous $3 \mathrm{D}$ materials remain preferable in their use as cathode materials in EAOPs processes. ${ }^{59-62}$

\subsubsection{Oxygen Reduction Reaction (ORR) Activity}

Oxygen reduction reaction (ORR) activity is responsible for $\mathrm{H}_{2} \mathrm{O}_{2}$ electrogeneration at cathode surface through the 2-electron reaction pathway (Eq. 1.1). $\mathrm{H}_{2} \mathrm{O}_{2}$ is part of the Fenton's reagent that promote the production of ${ }^{\circ} \mathrm{OH}$ radicals (Eq. 1.2) and degrade organic effluent from water/wastewater when implemented in specific EAOPs.

Linear scan voltammetry (LSV) is an efficient device to investigate the electrochemical reaction kinetics on electrode materials and specially to carry out the ORR activity. ${ }^{63-67}$ LSV can be performed with a potentiostat using a static working electrode ${ }^{12-14}$ or a rotating ring disk electrode $(\mathrm{RRDE})^{15}$ in a mixture of an electroactive specie $\left(\mathrm{K}_{3}\left[\mathrm{Fe}(\mathrm{CN})_{6}\right]\right)$ and an inert supporting electrolyte $(\mathrm{KCl})$. 
This method allows getting the polarization curves that reflect the transient current response with respect to the applied cathodic potential. Generally, LSV is first performed in $\mathrm{N}_{2}$-saturated solution, i.e. free of dissolved $\mathrm{O}_{2}$, meaning that oxygen reduction reaction (ORR) is inhibited so that only $\mathrm{H}_{2}$ evolution reaction (HER) occurs (Eq. 1.5): ${ }^{18}$

$2 \mathrm{H}^{+}+2 \mathrm{e}^{-} \rightarrow \mathrm{H}_{2(\mathrm{~g})}$

Then, LSV measurements are done in $\mathrm{O}_{2}$-saturated solution and both HER and ORR activity are monitored. The net current density can therefore be defined as the difference between the currents recorded in $\mathrm{O}_{2-}$ and $\mathrm{N}_{2}$-saturated solutions, determining the ORR activity of the working electrode. Thus, a higher net current density would suggest a higher ORR activity, i.e. a higher $\mathrm{H}_{2} \mathrm{O}_{2}$ electrogeneration efficiency (Eq. 1.1) and in the meantime a greater production of competitive waste 4-electron ORR pathway that produce $\mathrm{H}_{2} \mathrm{O}$ (Eq. 1.6): ${ }^{12,14,68}$

$\mathrm{O}_{2}+4 \mathrm{H}^{+}+4 \mathrm{e}^{-} \rightarrow 2 \mathrm{H}_{2} \mathrm{O}$

Due to the existence of competitive reactions, there exists an optimal applied cathodic potential that was reported to be in the range of $-0.5 \mathrm{~V}$ to $-0.75 \mathrm{~V}$ vs. SCE for carbonaceous materials (e.g. graphite, CVD Gmono, CVD Gmulti, CVD Gfoam, cloth, EEG-Cloth, N-rGO@CNT, CF, $\mathrm{CPrGO}-\mathrm{CF})^{12-15}$. At respective optimal cathodic potential value, the net current density (in absolute value) of each material have been compared in Fig. 1.6d. The following net current rank was noticed (expressed in $\mathrm{mA} \mathrm{cm}^{-2}$ ): CVD Gmono (0.00064) < CVD Gmulti $(0.00067)<$ CVD Gfoam $(0.018)<$ cloth $(0.022)<$ EEG-Cloth $(0.14)<$ CF $(2.00)<$ N-rGO@CNT $(2.50)<$ CPrGO-CF (16). It is interesting to note that CVD graphene materials portrayed lower ORR activity than other carbonaceous cathodes. The higher presence of oxygen-functional groups on rGO-based electrodes and raw cloth and CF materials could increase the ORR activity according to the following reactions (Eqs. $1.7 \mathrm{a}-7 \mathrm{~d}):^{60}$

$$
\begin{array}{lll}
\mathrm{C}=\mathrm{O}+\mathrm{e}^{-} & \rightarrow & \mathrm{C}=\mathrm{O}^{-} \\
\mathrm{C}=\mathrm{O}^{-}+\mathrm{O}_{2} & \rightarrow & \mathrm{C}=\mathrm{O}+\mathrm{O}_{2}^{-} \\
2 \mathrm{O}_{2}^{-}+\mathrm{H}_{2} \mathrm{O} & \rightarrow & \mathrm{O}_{2}+\mathrm{HO}_{2}^{-}+\mathrm{OH}^{-} \\
\mathrm{O}_{2}^{-}+\mathrm{H}_{2} \mathrm{O}+\mathrm{e}^{-} \rightarrow & \mathrm{HO}_{2}^{-}+\mathrm{OH}^{-}
\end{array}
$$

Still, 3D materials such as Gfoam and CPrGO-CF electrodes could enhance the ORR activity as compared to $2 \mathrm{D}$ materials. It has been previously reported that electrochemical processes occur at the carbon spaces rather than at the outer planar surface, resulting in a three- dimensional 
electrochemical activity, ${ }^{69}$ which was consistent with the better electrocatalytic activity gained with 3D materials.

In addition, EEG and CPrGO increased the ORR activity of the cloth by 6.4 -fold ${ }^{14}$ and of the CF by 8 -times ${ }^{12}$, respectively. The slight difference of efficiency between EEG and CPrGO could be referred to the numerous oxygen functionalities present on the later one.

Liu et al. ${ }^{15}$ further stated that N-rGO@CNT had higher ORR activity than rGO and CNT separately. The enhanced ORR activity could be ascribed to two main factors: (i) the easier electron transfer benefited from the bridge between CNT and graphene in the 3D assembly composite, and (ii) the nitrogen doping. The presence of nitrogen implies a dipole effect between $\mathrm{N}-\mathrm{C}$ bonds, meaning that the electron density of the three adjacent carbon atoms is lowered - the electronegativity of $\mathrm{N}$ (3.04) being higher than $\mathrm{C}(2.55)$ - thus favoring the chemisorption of $\mathrm{O}_{2}$ on positively charged carbon atoms and the subsequent ORR. ${ }^{70}$ Therefore, the synergy of graphene/CNT composite and the presence of N-doped carbons are both parameters that appear to be an interesting feature to take into account for electrode characterization and further development of novel graphene-based cathode materials.

After characterizations and comparisons of the different enhanced properties benefited from graphene-based electrodes, it appears interesting to evaluate their efficiency in real applications such as EAOPs for water/wastewater treatment as discussed in the following section 1.6.

\subsection{WATER/WASTEWATER TREATMENT APPLICATIONS OF GRAPHENE- BASED ELECTRODES}

\subsubsection{Context and Development of EAOPs}

Water scarcity is becoming a global concern that can be mainly imputed to the ever increasing water demand and the overall climate change. Additionally, the continuous release of POPs from municipal and industrial wastewater treatment plant that pollute the natural water bodies along with more and more stringent regulations, makes water/wastewater treatment one of the greatest challenge of the century. ${ }^{71}$ These POPs such as pesticides, pharmaceuticals, cosmetics, etc also characterized as micropollutants and/or emerging contaminants are known to be not only toxic to the environment and human health but also refractory to the current biological treatments. Regarding this context there is a need to develop advanced physico-chemical treatment able to eliminate such POPs from water. Advanced oxidation processes (AOPs) have been developed for this purpose. ${ }^{72}$ All AOPs rely on the production of ${ }^{\circ} \mathrm{OH}$ that has a very high oxidation potential ( $2.8 \mathrm{~V}$ vs. SHE $)^{73}$, second after fluorine that have to be avoided in a context 
of water remediation. This radical is non-selective and its reaction kinetics are even quicker with aromatic rings and double $\mathrm{C}=\mathrm{C}$ bonds $\left(10^{8}-10^{10} \mathrm{~L} \mathrm{~mol}^{-1} \mathrm{~s}^{-1}\right)$, major components of the xenobiotic compounds. ${ }^{18}$ Recently, EAOPs have emerged as they require only electrical power and optionally a supporting electrolyte in too low conductivity effluent. ${ }^{18-22}$ In contrast to the traditional AOPs (e.g. ozonation, Fenton technologies, photocatalysis, etc), the oxidants are produced in situ and continuously in mild conditions (room temperature and pressure) through the use of adequate catalytic electrode materials. ${ }^{18}$ Other advantages include high energy efficiency, easy handling, safety, modularity and versatility as EAOPs can treat a very wide range of effluents (i.e. from micropollution to highly loaded industrial effluent). ${ }^{20}$

In such processes, the electrode material is a key element of the system. Especially, carbonaceous cathode material can promote the Fenton reaction (Eq. 1.2) accountable for the $\cdot \mathrm{OH}$ formation in an electro-Fenton process. In this technology, $\mathrm{H}_{2} \mathrm{O}_{2}$ is electrogenerated through $\mathrm{O}_{2}$ reduction (Eq. 1.1) while ferrous ion $\left(\mathrm{Fe}^{2+}\right)$ is regenerated from ferric ion $\left(\mathrm{Fe}^{3+}\right)$ reduction (Eq. 1.8). ${ }^{74,75}$

$\mathrm{Fe}^{3+}+\mathrm{e}^{-} \rightarrow \mathrm{Fe}^{2+}$

The superiority of electro-Fenton over traditional chemical Fenton process remains also in the addition of only a catalytic amount $(0.05-0.2 \mathrm{mM})$ of iron source - if not already present in the effluent $-^{76,77}$, which restrain sludge production. In addition, the degradation and mineralization rates and yields can be very high (>99\%), even with refractory compounds. ${ }^{78-82}$

As explained in section 1.4.1, carbon-based cathode (e.g. carbon felt, graphite felt, PTFE-gas diffusion electrode (GDE)) manifested excellent performance in electro-Fenton process, but still the yield of $\mathrm{H}_{2} \mathrm{O}_{2}$ production and the rates of $\mathrm{Fe}^{2+}$ regeneration were not satisfying enough to scale-up the technology. ${ }^{13,14}$ Therefore, extensive efforts have been made to elevate the catalytic efficiency of carbonaceous cathodes via chemical modification ${ }^{60}$, electrochemical modification $^{66}$, acidic treatment ${ }^{83}$ or surface modification with organic compounds and rareearth- derived compounds ${ }^{84-88}$. More recently, the benefits that could be gained from graphenebased materials due to their exceptional properties (section 1.5) have been investigated for EAOPs applications. ${ }^{11-17}$ The results are presented and compared hereinafter by taking into account five criterion: (i) the $\mathrm{H}_{2} \mathrm{O}_{2}$ accumulation efficiency, (ii) the pollutant degradation efficiency, (iii) the mineralization efficiency, (iv) the stability of electrode and (v) the energy requirements. 


\subsection{2 $\quad \mathrm{H}_{2} \mathrm{O}_{2}$ Accumulation Concentration}

Being performed in undivided cell, the kinetics of $\mathrm{H}_{2} \mathrm{O}_{2}$ accumulation concentration that is produced in an electro-Fenton treatment display always the same trend whatever the applied current density, ie. a transient phase followed by a steady state. This behavior can be explained by the competition between $\mathrm{H}_{2} \mathrm{O}_{2}$ electrogeneration at the cathode (Eq. 1.1) and the $\mathrm{H}_{2} \mathrm{O}_{2}$ decomposition at the cathode (Eq. 1.9), at the anode (Eqs. 1.10a-10b) and in a lesser extent in the bulk solution (Eq. 1.11): ${ }^{18}$

$\begin{array}{lll}\mathrm{H}_{2} \mathrm{O}_{2}+2 \mathrm{H}^{+}+2 \mathrm{e}^{-} & \rightarrow & 2 \mathrm{H}_{2} \mathrm{O} \\ \mathrm{H}_{2} \mathrm{O}_{2} & \rightarrow & \mathrm{HO}_{2} \cdot+\mathrm{H}^{+}+\mathrm{e}^{-} \\ \mathrm{HO}_{2}{ }^{-} & \rightarrow & \mathrm{O}_{2}+\mathrm{H}^{+}+\mathrm{e}^{-} \\ 2 \mathrm{H}_{2} \mathrm{O}_{2} & \rightarrow & \mathrm{O}_{2}+2 \mathrm{H}_{2} \mathrm{O}\end{array}$

Varying the applied current density, and therefore the applied cathodic potential, further exhibited an optimal $\mathrm{H}_{2} \mathrm{O}_{2}$ accumulation concentration value. ${ }^{13,14}$ This is ascribed to the parasitic reactions, i.e. HER (Eq. 1.5) and $\mathrm{H}_{2} \mathrm{O}_{2}$ decomposition (Eqs. 1.9-11), that become dominating when the applied current density is too high (i.e. cathodic potential too low).

The maximal amounts of $\mathrm{H}_{2} \mathrm{O}_{2}$ accumulated in the cell using different graphene-based cathode material have been represented in Fig. 1.7a. ${ }^{13-16}$ The concentration values have been taken at optimal applied cathodic potential and normalized to the cathode area in order to be comparable. The following rank of maximal $\mathrm{H}_{2} \mathrm{O}_{2}$ accumulation concentration was given (expressed in $\mathrm{mg}$ $\mathrm{H}_{2} \mathrm{O}_{2} \mathrm{~L}^{-1} \mathrm{~cm}^{-2}$ ): CVD Gmono (0.032) < CVD Gmulti (0.048) < CVD Gfoam (0.213) < rGO $(0.5)<$ cloth $(1.43)<$ rGO@CNT (2.25) < EEG-Cloth $(2.81)<$ N-rGO@CNT (5) < rGOGraphite GDE (15.7). Among the CVD graphenes, 3D Gfoam highlighted again much better performance, which could be due to its higher electroactive surface area, conductivity and ORR activity. EEG-Cloth could increase by 2 times the $\mathrm{H}_{2} \mathrm{O}_{2}$ production from the raw cloth, indicating the benefit got from graphene. 4.6- and 6.7-fold improvements were noticed with NrGO@CNT as compared to $\mathrm{rGO} @ \mathrm{CNT}$ and rGO, respectively. It brings to light the synergy obtained with 3D assembly of rGO@CNT and the N-doped material. Interestingly, rGOGraphite GDE gave the better $\mathrm{H}_{2} \mathrm{O}_{2}$ production efficiency. GDE are known to generate high concentrations of $\mathrm{H}_{2} \mathrm{O}_{2}$ thanks to $\mathrm{O}_{2}$ bubbling through the carbon material which ensures enhanced contact between the cathode surface and $\mathrm{O}_{2} \cdot{ }^{75}$ However, GDE cathodes typically suffer from reduced surface area as compared to $3 \mathrm{D}$ carbon materials, leading to lower $\mathrm{Fe}^{2+}$ regeneration and therefore $\mathrm{Fe}^{3+}$ accumulation and lower production of ${ }^{\circ} \mathrm{OH} .{ }^{75}$ Moreover, $\mathrm{Xu}$ et 
al. ${ }^{16}$ did not compare the degradation and mineralization efficiencies of their graphene material with an uncoated cathode which does not allow for complete comparison in terms of the coating efficiency.

\subsubsection{Pollution Degradation Efficiency}

EAOPs are able to degrade many kinds of pollutants and mainly dyes (brilliant blue ${ }^{16}$, methylene blue ${ }^{17}$ and acid orange $7^{11,12}$ ), phenolic compounds ${ }^{13,14}$ and plastic additives (dimethyl phthalate) ${ }^{15}$ have been treated by electro-Fenton using graphene-based cathode (Table 1.2). Electro-Fenton process successfully degraded all monitored contaminants thanks to the very high oxidation power of ${ }^{\circ} \mathrm{OH}$ that react mainly through two mechanisms: (i) hydrogen atom abstraction (e.g. aliphatics (R)) (Eqs. 1.12a-12c) or (ii) by electrophilic addition to an unsaturated bond (e.g. aromatics (Ar)) (Eqs. 1.13a-13c) to initiate a radical oxidation chain: ${ }^{18,20}$

$$
\begin{aligned}
& \mathrm{RH}+{ }^{\circ} \mathrm{OH} \rightarrow \mathrm{H}_{2} \mathrm{O}+\mathrm{R}^{\cdot} \\
& \mathrm{R}^{\cdot}+\mathrm{O}_{2} \rightarrow \mathrm{ROO}^{\bullet} \\
& \mathrm{ROO}+\mathrm{RH} \rightarrow \mathrm{ROOH}+\mathrm{R}^{\cdot} \\
& \mathrm{ArH}+{ }^{\circ} \mathrm{OH} \rightarrow \operatorname{ArH}(\mathrm{OH})^{\circ} \\
& \operatorname{ArH}(\mathrm{OH})^{\cdot}+\mathrm{O}_{2} \rightarrow[\operatorname{ArH}(\mathrm{OH}) \mathrm{OO}]^{\cdot} \\
& {[\operatorname{ArH}(\mathrm{OH}) \mathrm{OO}]^{\cdot} \rightarrow \operatorname{ArH}(\mathrm{OH})+\mathrm{HO}_{2}{ }^{\cdot}}
\end{aligned}
$$

Most of the time, at the beginning of the oxidation treatment the pollutant decay follows a pseudo-first-order kinetic model, assuming a quasi-stationary state for ${ }^{\circ} \mathrm{OH}$ concentration as it does not accumulate into the solution $\left(\left[{ }^{*} \mathrm{OH}\right]\right)($ Eq. 1.14):

$\frac{d[\text { pollutant }]}{d t}=-k_{\text {abs }}[\bullet \mathrm{OH}][$ pollutant $]=k_{\text {app }}[$ pollutant $]$

where $k_{\mathrm{abs}}$ is the absolute rate constant of pollutant decay and $k_{\text {app }}$ is the pseudo-first order rate constant of pollutant decay.

After integration of Eq. 1.14, the following relation is obtained (Eq. 1.15):

$$
\ln \left(\frac{[\text { pollutant }]_{0}}{[\text { pollutant }]}\right)=k_{\text {app }} t
$$

Then $k_{\text {app }}$ values can be deduced from linear regression of the semi-logarithmic plots. $k_{\text {app }}$ value is an efficient parameter that allow comparing the degradation efficiencies of different operating conditions and processes. This constant is often converted into the half-life time $\left(t_{1 / 2}\right)$, which is 
the time to degrade $50 \%$ of the monitored contaminant. $t_{1 / 2}$ values have been reported in Table 1.2 for each electro-Fenton treatment employing a graphene-based cathode. CVD graphene setups allowed degrading $50 \%$ of phenol $(1 \mathrm{mM})$ after $86 \mathrm{~min}$ (Gfoam), $315 \mathrm{~min}$ (Gmulti) and 866 min (Gmono). ${ }^{13}$ The rate of phenol decay with Gfoam was 3.7 and 10 times faster than Gmulti and Gmono, respectively. This trend was in agreement with the higher conductivity (section 1.5.3), higher electroactive surface area (section 1.5.4) and higher ORR activity (section 1.5.5) of Gfoam. ${ }^{13}$ It allows electrogenerating the Fenton reagent (especially $\mathrm{H}_{2} \mathrm{O}_{2}$ (section 1.6.2)) at higher rates and yield. ${ }^{13}$ In similar operating conditions, EEG-Cloth could decrease by 3.1 fold the half-life time of phenol (44 $\mathrm{min}$ ) as compared to the raw cloth (136 min). Again, the higher conductivity, electroactive surface area and ORR activity led to higher amount of ${ }^{\circ} \mathrm{OH}$ produced and quicker contaminant degradation rates. Comparatively, CPrGO$\mathrm{CF}$ increased by 2.2 times the degradation rates efficiency of acid orange 7 as compared to the raw CF. Interestingly, Liu et al. ${ }^{15}$ further exhibited the gain (4 to 16.2 times of increase) that could be obtained using a N-rGO@CNT-based cathode $\left(t_{1 / 2}=21.4 \mathrm{~min}\right)$ as compared to a rGO@CNT $\left(t_{1 / 2}=86.6 \mathrm{~min}\right)$ and rGO-based cathode $\left(t_{1 / 2}=347 \mathrm{~min}\right)$ when degrading dimethyl phthalate.

\subsubsection{Mineralization Efficiency}

EAOPs and especially electro-Fenton offer the possibility to mineralize quasi-completely the effluent after an extended treatment, i.e. to reach the quasi-total conversion of organic compounds into $\mathrm{CO}_{2}, \mathrm{H}_{2} \mathrm{O}$ and inorganic ions when heteroatoms are present. The oxidation pathway leads to the ring-opening reactions (Eq. 1.16) of the hydroxylated aromatic compounds $(\mathrm{ArOH})$ initially formed (Eqs. 1.13a-13c): $:^{89,90}$

$\mathrm{Ar}(\mathrm{OH})+{ }^{\cdot} \mathrm{OH} / \mathrm{O}_{2} \rightarrow \mathrm{CA}+\mathrm{CO}_{2}$

Carboxylic acids are then degraded to form shorter chain CAs (Eq. 1.17): ${ }^{89-91}$

$\mathrm{CA}_{1}+\cdot \mathrm{OH} / \mathrm{O}_{2} \rightarrow \mathrm{CA}_{2}+\mathrm{CO}_{2}$

These low molecular weight CA, e.g. oxalic acid, formic acid and acetic acid, constitute generally the latest organic products because they are directly converted into $\mathrm{CO}_{2}$ and $\mathrm{H}_{2} \mathrm{O}$ (Eq. $1.18):{ }^{89-91}$ 
$\mathrm{CA}_{2}, \mathrm{CA}_{3}, \ldots \mathrm{CA}_{\mathrm{n}}+{ }^{\cdot} \mathrm{OH} / \mathrm{O}_{2} \rightarrow \mathrm{CO}_{2}+\mathrm{H}_{2} \mathrm{O}$

Total organic carbon (TOC) measurements are usually performed in order to obtain the mineralization degree, considering that mineralization yields are equivalent to TOC removal ${ }^{13}$. TOC decay have been previously monitored during an electro-Fenton treatment with different graphene-based electrodes. ${ }^{11-14}$ It is interesting to note that in all the case, the TOC decay rates decreased towards the end of treatment. This trend is related to the increased formation of CAs and especially short-chain CAs that are more recalcitrant to mineralization, with rate constants of reaction with ${ }^{\circ} \mathrm{OH}$ ranging from $1.4 \times 10^{6} \mathrm{~L} \mathrm{~mol}^{-1} \mathrm{~s}^{-1}$ (oxalic acid) to $1.3 \times 10^{8} \mathrm{~L} \mathrm{~mol}^{-1} \mathrm{~s}^{-1}$ (acetic acid). ${ }^{13,91}$ In the meantime, several waste reactions such as between ${ }^{\circ} \mathrm{OH}$ and $\mathrm{Fe}^{2+}$ (Eq. 1.19) and between ${ }^{\circ} \mathrm{OH}$ and $\mathrm{H}_{2} \mathrm{O}_{2}$ (Eq. 1.20), become predominant and compete with the Fenton reaction (Eq. 1.2):

$\mathrm{Fe}^{2+}+{ }^{\circ} \mathrm{OH} \rightarrow \mathrm{Fe}^{3+}+\mathrm{HO}^{-}$

$\mathrm{H}_{2} \mathrm{O}_{2}+{ }^{\circ} \mathrm{OH} \rightarrow \mathrm{H}_{2} \mathrm{O}+\mathrm{HO}_{2} \cdot$

Regarding the mineralization yield, CVD graphene could reach $1.9 \%, 5.3 \%$ and $14.2 \%$ with Gmono, Gmulti and Gfoam, respectively after $2 \mathrm{~h}$ of electro-Fenton treatment (Table 1.2), highlighting again the superiority of the 3D Gfoam. ${ }^{13}$ The presence of EEG on carbon cloth could reach higher mineralization yield (16.0\%), a 1.5-times improvement as compared to the raw cloth (10.6\%). ${ }^{14} \mathrm{~A}$ lower enhancement was noticed (1.3 times) between CPrGO-CF (74\%) and CF (56\%). ${ }^{12}$ From 2 to 10 times improvement of rGO@CNT (19\% of mineralization yield) and rGO materials (4\% of mineralization yield) was reached with N-rGO@CNT electrode (40\% of mineralization yield). ${ }^{15}$ These trends corroborated the results given in sections 1.6.3 and 1.6.4.

\subsubsection{Stability of Electrode}

The stability of graphene-based electrodes is a crucial factor that need to be assessed before the development of EAOPs for environmental applications. In this context, electro-Fenton treatments are repeated several times in a row, from 5 successive batches ${ }^{14}$ to 7 cycles, ${ }^{17} 10$ cycles $^{12,13}$ and 20 cycles $^{15}$, according to the literature. The values represented in Table 1.2 reproduce the percentage of 2 h-electro-Fenton degradation ${ }^{15,17}$ or mineralization ${ }^{12-14}$ after the $1^{\text {st }}$ and the $5^{\text {th }}$ cycle. The stability of the graphene-based cathode can be ranked as follow from the least stable (expressed in \% of stability decrease): CVD Gmono $(100 \%)<$ EEG-Cloth $(21 \%)<$ 
CVD Gfoam $(13.4 \%)<$ CVD Gmulti $(7.5 \%)<$ CPrGO-CF $(6 \%)<$ rGO $(\sim 0 \%) \approx$ N-rGO@CNT $(\sim 0 \%)$. It was clear that CVD Gmono was not stable at all, which rule out its use as a single cathode. The stability of EEG-Cloth was decreasing with the number of cycles but still showed $5.3 \%$ higher mineralization yield than the uncoated cloth (10.6\%) after 5 cycles. CVD Gfoam and CVD Gmulti depicted better stability but the percentage of stability decrease is not completely representative to the stability of these materials. Five more successive cycles demonstrating the existence of a plateau, highlighting the stabilization behavior of these CVD materials. Contrastingly, the decrease percentage was $6 \%$ with $\mathrm{CPrGO}-\mathrm{CF}$; however, pursuing the successive treatments over 10 cycles makes decrease again the stability until a $14 \%$ decrease of stability. Interestingly, rGO-based cathode from Zhao et al. ${ }^{17}$ and N-rGO@CNT material displayed very good stability. Nevertheless, the assessment of stability was performed by monitoring the degradation of pollutant, unlike the other works. It overestimates the real stability as it has been established previously. For instance, decrease percentages of stability equaled $2.5 \%$ with Gmulti and $0.8 \%$ with Gfoam after 10 cycles of $2 \mathrm{~h}$ of electro-Fenton degradation, which was much better than monitoring the mineralization. ${ }^{13}$ It can be further perceived that the coating procedure of EEG-Cloth and CPrGO-CF need to be improved.

\subsubsection{Energy Requirements}

In EAOPs the electrical power is an important feature as it corresponds to the main operating cost. Therefore, reducing the energy consume ( $\left.E_{\text {consumption }}\right)$ is a decisive step before implementing such processes in industrial applications. Energy requirements are often considered per amount of TOC removed and can be calculated according to the following relation (Eq. 1.21):

$\mathrm{E}_{\text {consumption }}\left(\mathrm{kWh} g^{-1} \mathrm{TOC}\right)=\frac{\mathrm{E}_{\text {cell }} \mathrm{It}}{(\triangle \mathrm{TOC})_{\mathrm{t}} \mathrm{V}_{\mathrm{S}}}$

where $E_{\text {cell }}$ is the average cell voltage $(\mathrm{V}), I$ is the applied current (A), $t$ is the electrolysis time (h), $V_{s}$ is the solution volume (L), and $\Delta(\mathrm{TOC})_{\mathrm{t}}$ is the TOC decay $\left(\mathrm{mg}-\mathrm{C} \mathrm{L}^{-1}\right)$.

The energies consumed to reach $40 \%$ of mineralization were ranked as follow (Table 1.2): CVD Gfoam $\left(0.039 \mathrm{kWh} \mathrm{g}^{-1}\right.$ TOC) < CVD Gmulti $\left(0.053 \mathrm{kWh} \mathrm{g}^{-1}\right.$ TOC $)<$ CVD Gmono $(0.072 \mathrm{kWh}$ $\mathrm{g}^{-1}$ TOC $)<$ carbon cloth $\left(0.31 \mathrm{kWh} \mathrm{g}^{-1}\right.$ TOC $)<$ EEG-Cloth $\left(0.20 \mathrm{kWh} \mathrm{g}^{-1}\right.$ TOC $)<\mathrm{CF}(0.74$ $\mathrm{kWh} \mathrm{g}^{-1}$ TOC $)<\mathrm{CPrGO}-\mathrm{CF}\left(0.53 \mathrm{kWh} \mathrm{g}^{-1} \mathrm{TOC}\right)$. Interestingly, the CVD graphene materials required much lower energy to be performed than the other carbon-based cathodes. Still, a 1.6fold improvement of the EEG-Cloth against the raw cloth could be obtained while a 1.4-times 
enhancement was procured by the CPrGO-CF over the uncoated $\mathrm{CF}$. The positive role of graphene is again emphasized and could be even surpassed as it has been showed a 4.3 decrease of energy when using N-rGO@CNT instead of rGO.

\subsection{CONCLUDING REMARKS}

The use of graphene-based electrodes has been reviewed from the synthesis and characterization of graphene to the manufacture of electrode and finally to their applications in EAOPs for water/wastewater treatment. Different factors have shown to affect the performance (in terms of $\mathrm{H}_{2} \mathrm{O}_{2}$ accumulation concentration, pollutant degradation and mineralization efficiency) of the graphene-based cathode in EAOPs treatment. Those parameters have been listed in Table 1.3 and the main impacted materials properties have been defined.

The comparison of these different factors allow identifying the two major properties of the materials that influence its efficiency in EAOPs applications (Fig. 1.8): (i) the conductivity of materials that increase the kinetics rates of electrochemical reaction and (ii) the specific surface area that raise the number of active sites for molecules reduction.

The purity of graphene materials has demonstrated to have adverse effects; lower defects make increase the conductivity while it makes decrease the ORR activity. Similarly, the hydrophilicity has contrasting impacts; higher hydrophilicity can favor the kinetics of gaseous $\mathrm{O}_{2}$ reduction while it can decrease the dissolved $\mathrm{O}_{2}$ reduction rate in the meanwhile. Therefore, the purity and hydrophilicity of materials could be considered having a secondary role in the electrocatalytic efficiency of the electrode.

Finally, the way to improve the electrocatalytic properties of nanostructured cathodes in EAOPs applications (Fig. 1.8) is to (i) employ raw carbonaceous materials (such as graphene), (ii) which can be coated with nanomaterials (graphene and/or CNT), (iii) by using preferentially porous 3D primary materials, and (iv) that can be doped with nitrogen. Such electrodes need to be developed in the near future in order to proceed to real applications.

\section{ACKNOWLEDGMENT}

This work was partially supported by Key Project of Natural Science Foundation of Tianjin (no. 16JCZDJC39300) and Natural Science Foundation of China (51178225 and 21273120) 


\section{REFERENCES}

(1) Geim, A.; Novoselov, K. The Rise of Graphene. Nat. Mater. 2007, 183-191.

(2) Morozov, S. V; Novoselov, K. S.; Katsnelson, M. I.; Schedin, F.; Elias, D. C.; Jaszczak, J. A.; Geim, A. K. Giant Intrinsic Carrier Mobilities in Graphene and Its Bilayer. 2008, 16602 (January), 11-14.

(3) Balandin, A. A.; Ghosh, S.; Bao, W.; Calizo, I.; Teweldebrhan, D.; Miao, F.; Lau, C. N. Superior Thermal Conductivity of Single-Layer Graphene 2008. 2008.

(4) Lee, C.; Wei, X.; Kysar, J. W.; Hone, J. Measurement of the Elastic Properties and Intrinsic Strength of Monolayer Graphene. Science (80-. ). 2008, 321, 385-388.

(5) Nair, R. R.; Blake, P.; Grigorenko, A. N.; Novoselov, K. S.; Booth, T. J.; Stauber, T.; Peres, N. M. R.; Geim, A. K. Fine Structure Constant Defines Visual Transparency of Graphene. Science. 2008, 320, 1308.

(6) Stoller, M. D.; Park, S.; Yanwu, Z.; An, J.; Ruoff, R. S. Graphene-Based Ultracapacitors. Nano Lett. 2008, 8 (10), 3498-3502.

(7) Chowdhury, S.; Balasubramanian, R. Graphene/semiconductor Nanocomposites (GSNs) for Heterogeneous Photocatalytic Decolorization of Wastewaters Contaminated with Synthetic Dyes: A Review. Appl. Catal. B Environ. 2014, 160-161, 307-324.

(8) Goh, P. S.; Ismail, A. F. Graphene-Based Nanomaterial: The State-of-the-Art Material for Cutting Edge Desalination Technology. Desalination 2014, 315 (2013), 115-128.

(9) Chowdhury, S.; Balasubramanian, R. Recent Advances in the Use of Graphene-Family Nanoadsorbents for Removal of Toxic Pollutants from Wastewater. Adv. Colloid Interface Sci. 2014, 204, 35-56.

(10) Filip, J.; Tkac, J. Is Graphene Worth Using in Biofuel Cells? Electrochim. Acta 2014, $136,340-354$.

(11) Le, T. X. H.; Bechelany, M.; Champavert, J.; Cretin, M. A Highly Active Based Graphene Cathode for the Electro-Fenton Reaction. RSC Adv. 2015, 5 (53), 4253642539.

(12) Le, T. X. H.; Bechelany, M.; Lacour, S.; Oturan, N.; Oturan, M. A.; Cretin, M. High Removal Efficiency of Dye Pollutants by Electron-Fenton Process Using a Graphene Based Cathode. Carbon N. Y. 2015, 94, 1003-1011.

(13) Mousset, E.; Wang, Z.; Hammaker, J.; Lefebvre, O. Physico-Chemical Properties of Pristine Graphene and Its Performance as Electrode Material for Electro-Fenton Treatment of Wastewater. Electrochim. Acta 2016, 214, 217-230.

(14) Mousset, E.; Ko, Z. T.; Syafiq, M.; Wang, Z.; Lefebvre, O. Electrocatalytic Activity Enhancement of a Graphene Ink-Coated Carbon Cloth Cathode for Oxidative Treatment. Electrochim. Acta 2016, 1-14.

(15) Liu, T.; Wang, K.; Song, S.; Brouzgou, A.; Tsiakaras, P.; Wang, Y. New Electro-Fenton Gas Diffusion Cathode Based on Nitrogen-Doped Graphene@carbon Nanotube Composite Materials. Electrochim. Acta 2016, 194.

(16) Xu, X.; Chen, J.; Zhang, G.; Song, Y.; Yang, F. Homogeneous Electro-Fenton Oxidative Degradation of Reactive Brilliant Blue Using a Graphene Doped Gas-Diffusion Cathode. Int. J. Electrochem. Sci. 2014, 9, 569-579.

(17) Zhao, F.; Liu, L.; Yang, F.; Ren, N. E-Fenton Degradation of MB during Filtration with Gr/PPy Modified Membrane Cathode. Chem. Eng. J. 2013, 230, 491-498.

(18) Brillas, E.; Sirés, I.; Oturan, M. A. Electro-Fenton Process and Related Electrochemical Technologies Based on Fenton's Reaction Chemistry. Chem. Rev. 2009, 109 (12), 65706631.

(19) Rodrigo, M. A.; Oturan, N.; Oturan, M. A. Electrochemically Assisted Remediation of Pesticides in Soils and Water: A Review. Chem. Rev. 2014, 114 (17), 8720-8745. 
(20) Sirés, I.; Brillas, E.; Oturan, M. A.; Rodrigo, M. A.; Panizza, M. Electrochemical Advanced Oxidation Processes: Today and Tomorrow. A Review. Environ. Sci. Pollut. Res. Int. 2014, 21 (14), 8336-8367.

(21) Martinez-Huitle, C. A.; Rodrigo, M. A.; Sires, I.; Scialdone, O. Single and Coupled Electrochemical Processes and Reactors for the Abatement of Organic Water Pollutants : A Critical Review. Chem. Rev. 2015, 115 (24), 13362-13407.

(22) Moreira, F. C.; Boaventura, R. A. R.; Brillas, E.; Vilar, V. J. P. Electrochemical Advanced Oxidation Processes: A Review on Their Application to Synthetic and Real Wastewaters. Appl. Catal. B Environ. 2017, 202, 217-261.

(23) Zhao, G.; Wen, T.; Chen, C.; Wang, X. Synthesis of Graphene-Based Nanomaterials and Their Application in Energy-Related and Environmental-Related Areas. RSC Adv. 2012, 2 (25), 9286-9303.

(24) Ambrosi, A.; Chua, C. K.; Bonanni, A.; Pumera, M. Electrochemistry of Graphene and Related Materials. Chem. Rev. 2014, 114 (14), 7150-7188.

(25) Muñoz, R.; Gómez-Aleixandre, C. Review of CVD Synthesis of Graphene. Chem. Vap. Depos. 2013, 19 (10-11-12), 297-322.

(26) Li, X.; Cai, W.; An, J.; Kim, S.; Nah, J.; Yang, D.; Piner, R.; Velamakanni, A.; Jung, I.; Tutuc, E.; et al. Large Area Synthesis of High Quality and Uniform Graphene Films on Copper Foils. Science (80-. ). 2009, 324 (5932), 1312-1314.

(27) Chen, Z.; Ren, W.; Gao, L.; Liu, B.; Pei, S.; Cheng, H.-M. Three-Dimensional Flexible and Conductive Interconnected Graphene Networks Grown by Chemical Vapour Deposition. Nat. Mater. 2011, 10 (6), 424-428.

(28) Bae, S.; Kim, H.; Lee, Y.; Xu, X.; Park, J.-S.; Zheng, Y.; Balakrishnan, J.; Lei, T.; Ri Kim, H.; Song, Y. Il; et al. Roll-to-Roll Production of 30-Inch Graphene Films for Transparent Electrodes. Nat. Nanotechnol. 2010, 5 (8), 574-578.

(29) Liang, X.; Sperling, B. a.; Calizo, I.; Cheng, G.; Hacker, C. A.; Zhang, Q.; Obeng, Y.; Yan, K.; Peng, H.; Li, Q.; et al. Toward Clean and Crackless Transfer of Graphene. ACS Nano 2011, 5 (11), 9144-9153.

(30) Moraes, F. C.; Gorup, L. F.; Rocha, R. S.; Lanza, M. R. V; Pereira, E. C. Photoelectrochemical Removal of 17 beta-Estradiol Using a $\mathrm{RuO}_{2}$-Graphene Electrode. Chemosphere 2016, 162, 99-104.

(31) Hummers, W. S.; Offeman, R. E. Preparation of Graphitic Oxide. J. Am. Chem. Soc. 1958, 80 (6), 1339-1339.

(32) Marcano, D. C.; Kosynkin, D. V; Berlin, J. M.; Sinitskii, A.; Sun, Z.; Slesarev, A.; Alemany, L. B.; Lu, W.; Tour, J. M. Improved Synthesis of Graphene Oxide. ACS Nano 2010, 4 (8), 4806-4814.

(33) Zhang, J.; Yang, H.; Shen, G.; Cheng, P.; Zhang, J.; Guo, S. Reduction of Graphene Oxide via L-Ascorbic Acid. Chem. Commun. 2010, 46 (7), 1112-1114.

(34) Parvez, K.; Wu, Z. S.; Li, R.; Liu, X.; Graf, R.; Feng, X.; Müllen, K. Exfoliation of Graphite into Graphene in Aqueous Solutions of Inorganic Salts. J. Am. Chem. Soc. 2014, 136 (16), 6083-6091.

(35) Parvez, K.; Li, R.; Puniredd, S. R.; Hernandez, Y.; Hinkel, F.; Wang, S.; Feng, X.; Mu, K.; Engineering, C.; Road, D. Electrochemically Exfoliated Graphene as SolutionProcessable, Highly Conductive Electrodes for Organic Electronics. ACS Nano 2013, 7 (4), 3598-3606.

(36) Su, C. Y.; Lu, A. Y.; Xu, Y.; Chen, F. R.; Khlobystov, A. N.; Li, L. J. High-Quality Thin Graphene Films from Fast Electrochemical Exfoliation. ACS Nano 2011, 5 (3), 23322339.

(37) Wu, L.; Li, W.; Li, P.; Liao, S.; Qiu, S.; Chen, M.; Guo, Y.; Li, Q.; Zhu, C.; Liu, L. Powder, Paper and Foam of Few-Layer Graphene Prepared in High Yield by Electrochemical Intercalation Exfoliation of Expanded Graphite. Small 2014, 10 (7), 1421-1429.

(38) Guo, J.; Zhang, T.; Hu, C.; Fu, L. A Three-Dimensional Nitrogen-Doped Graphene 
Structure: A Highly Efficient Carrier of Enzymes for Biosensors. Nanoscale 2015, 7 (4), 1290-1295.

(39) Krauss, B.; Lohmann, T.; Chae, D. H.; Haluska, M.; Von Klitzing, K.; Smet, J. H. LaserInduced Disassembly of a Graphene Single Crystal into a Nanocrystalline Network. Phys. Rev. B - Condens. Matter Mater. Phys. 2009, 79 (16), 1-16.

(40) Ferrari, A. C.; Robertson, J. Raman Spectroscopy of Amorphous, Nanostructured, Diamond-like Carbon, and Nanodiamond. Philos. Trans. A. Math. Phys. Eng. Sci. 2004, 362 (1824), 2477-2512.

(41) Kovtyukhova, N. I.; Ollivier, P. J.; Martin, B. R.; Mallouk, T. E.; Chizhik, S. a.; Buzaneva, E. V.; Gorchinskiy, A. D. Layer-by-Layer Assembly of Ultrathin Composite Films from Micron-Sized Graphite Oxide Sheets and Polycations. Chem. Mater. 1999, 11 (3), 771-778.

(42) Schroder, D. K. Semiconductor Material and Device Characterization, Third Ed.; John Wiley \& Sons: New York, NY, 2006.

(43) Pei, S.; Cheng, H. M. The Reduction of Graphene Oxide. Carbon. 2012, 50 (9), 32103228.

(44) Filik, H.; Çetintaş, G.; Koç, S. N.; Gülce, H.; Boz, İ. Nafion-Graphene Composite Film Modified Glassy Carbon Electrode for Voltammetric Determination of P-Aminophenol. Russ. J. Electrochem. 2014, 50 (3), 243-252.

(45) Wei, B.; Tokash, J. C.; Chen, G.; Hickner, M. A.; Logan, B. E. Development and Evaluation of Carbon and Binder Loading in Low-Cost Activated Carbon Cathodes for Air-Cathode Microbial Fuel Cells. Rsc Adv. 2012, 2 (33), 12751-12758.

(46) Liu, L.; Zhao, F.; Liu, J.; Yang, F. Preparation of Highly Conductive Cathodic Membrane with Graphene (oxide)/PPy and the Membrane Antifouling Property in Filtrating Yeast Suspensions in EMBR. J. Memb. Sci. 2013, 437, 99-107.

(47) Zhou, M.; Yu, Q.; Lei, L. The Preparation and Characterization of a graphite-PTFE Cathode System for the Decolorization of C.I. Acid Red 2. Dye. Pigment. 2008, 77 (1), 129-136.

(48) Pokpas, K.; Zbeda, S.; Jahed, N.; Mohamed, N.; Baker, P. G.; Iwuoha, E. I. NafionGraphene Nanocomposite in Situ Plated Bismuth-Film Electrodeon Pencil Graphite Substrates for the Determination of Trace Metals by Anodic Stripping Voltammetry. Int. J. Electrochem. Sci. 2014, 9 (2), 5092-5115.

(49) Gibney, E. 2D or Not 2D. Nature 2015, 522, 274-276.

(50) Le, T. X. H.; Bechelany, M.; Champavert, J.; Cretin, M. Support Information-A Highly Active Based Graphene Cathode for the Electro-Fenton Reaction. RSC Adv. 2015, 5 (53), 42536-42539.

(51) Lv, Z.; Chen, Y.; Wei, H.; Li, F.; Hu, Y.; Wei, C.; Feng, C. One-Step Electrosynthesis of Polypyrrole/graphene Oxide Composites for Microbial Fuel Cell Application. Electrochim. Acta 2013, 111, 366-373.

(52) Rafiee, J.; Mi, X.; Gullapalli, H.; Thomas, A. V; Yavari, F.; Shi, Y.; Ajayan, P. M.; Koratkar, N. a. Wetting Transparency of Graphene. Nat. Mater. 2012, 11 (3), 217-222.

(53) Chen, Z.; Ren, W.; Gao, L.; Liu, B.; Pei, S.; Cheng, H.-M. Three-Dimensional Flexible and Conductive Interconnected Graphene Networks Grown by Chemical Vapour Deposition. Nat. Mater. 2011, 10 (6), 424-428.

(54) Hass, J.; Varchon, F.; Millán-Otoya, J. E.; Sprinkle, M.; Sharma, N.; de Heer, W. A.; Berger, C.; First, P. N.; Magaud, L.; Conrad, E. H. Why Multilayer Graphene on 4HSiC(0001) Behaves Like a Single Sheet of Graphene. Phys. Rev. Lett. 2008, 100 (12), 125504(4).

(55) Morcos, I.; Yeager, E. Kinetic Studies of the Oxygen-peroxide Couple on Pyrolytic Graphite. Electrochim. Acta 1970, 15, 953-975.

(56) Yeager, E. Dioxygen Electrocatalysis: Mechanisms in Relation to Catalyst Structure. $J$. Mol. Catal. 1986, 38, 5-25.

(57) Bard, A. J.; Faulkner, L. R. Electrochemical Methods: Fundamentals and Applications; 
John Wiley \& Sons: New York, NY, 2000.

(58) Grewal, Y. S.; Shiddiky, M. J. A.; Gray, S. A.; Weigel, K. M.; Cangelosi, G. A.; Trau, M. Label-Free Electrochemical Detection of an Entamoeba Histolytica Antigen Using Cell-Free Yeast-scFv Probes. Chem. Commun. 2013, 49 (15), 1551-1553.

(59) Yu, X.; Zhou, M.; Ren, G.; Ma, L. A Novel Dual Gas Diffusion Electrodes System for Efficient Hydrogen Peroxide Generation Used in Electro-Fenton. Chem. Eng. J. 2015, 263, 92-100.

(60) Zhou, L.; Zhou, M.; Hu, Z.; Bi, Z.; Serrano, K. G. Chemically Modified Graphite Felt as an Efficient Cathode in Electro-Fenton for P-Nitrophenol Degradation. Electrochim. Acta 2014, 140, 376-383.

(61) Ma, L.; Zhou, M.; Ren, G.; Yang, W.; Liang, L. A Highly Energy-Efficient Flowthrough Electro-Fenton Process for Organic Pollutants Degradation. Electrochim. Acta 2016, 200, 222-230.

(62) Hu, J.; Sun, J.; Yan, J.; Lv, K.; Zhong, C.; Deng, K.; Li, J. A Novel Efficient Electrode Material: Activated Carbon Fibers Grafted by Ordered Mesoporous Carbon. Electrochem. commun. 2013, 28, 67-70.

(63) Hu, Z.; Zhou, M.; Zhou, L.; Li, Y.; Zhang, C. Effect of Matrix on the Electrochemical Characteristics of $\mathrm{TiO}_{2}$ Nanotube Array-Based $\mathrm{PbO}_{2}$ Electrode for Pollutant Degradation. Environ. Sci. Pollut. Res. Int. 2014, 21 (14), 8476-8484.

(64) Ding, Z.; Hu, X.; Morales, V. L.; Gao, B. Filtration and Transport of Heavy Metals in Graphene Oxide Enabled Sand Columns. Chem. Eng. J. 2014, 257, 248-252.

(65) Zhou, M.; Yu, Q.; Lei, L.; Barton, G. Electro-Fenton Method for the Removal of Methyl Red in an Efficient Electrochemical System. Sep. Purif. Technol. 2007, 57 (2), 380-387.

(66) Zhou, L.; Zhou, M.; Zhang, C.; Jiang, Y.; Bi, Z.; Yang, J. Electro-Fenton Degradation of P-Nitrophenol Using the Anodized Graphite Felts. Chem. Eng. J. 2013, 233, $185-192$.

(67) Yu, F.; Zhou, M.; Zhou, L.; Peng, R. A Novel Electro-Fenton Process with $\mathrm{H}_{2} \mathrm{O}_{2}$ Generation in a Rotating Disk Reactor for Organic Pollutant Degradation. Environ. Sci. Technol. Lett. 2014, 1, 320-324.

(68) Zhang, H.; Li, H.; Deng, C.; Zhao, B.; Yang, J. Electrocatalysis of Oxygen Reduction Reaction on Carbon Nanotubes Modified by Graphitization and Amination. ECS Electrochem. Lett. 2015, 4 (8), H33-H37.

(69) Frysz, C. A.; Shui, X.; Chung, D. D. L. Electrochemical Behavior of Porous Carbons. Carbon N. Y. 1997, 35 (7), 893-916.

(70) $\mathrm{Hu}, \mathrm{X}$.; $\mathrm{Wu}, \mathrm{Y}$.; Li, H.; Zhang, Z. Adsorption and Activation of $\mathrm{O}_{2}$ on Nitrogen-Doped Carbon Nanotubes. J. Phys. Chem. C 2010, 114 (21), 9603-9607.

(71) Sedlak, D. L. Water 4.0; Yale University Press, 2014.

(72) Oturan, M. A.; Aaron, J.-J. Advanced Oxidation Processes in Water/Wastewater Treatment: Principles and Applications. A Review. Crit. Rev. Environ. Sci. Technol. 2014, 44 (23), 2577-2641.

(73) Latimer, W. M. Oxidation Potentials. Soil Sci. 1952, 74 (4), 333.

(74) Oturan, M. A. An Ecologically Effective Water Treatment Technique Using Electrochemically Generated Hydroxyl Radicals for in Situ Destruction of Organic Pollutants: Application to Herbicide 2,4-D. J. Appl. Electrochem. 2000, 30 (4), 475-482.

(75) Sirés, I.; Garrido, J. A.; Rodríguez, R. M.; Brillas, E.; Oturan, N.; Oturan, M. a. Catalytic Behavior of the $\mathrm{Fe}^{3+} / \mathrm{Fe}^{2+}$ System in the Electro-Fenton Degradation of the Antimicrobial Chlorophene. Appl. Catal. B Environ. 2007, 72 (3-4), 382-394.

(76) Mousset, E.; Huguenot, D.; Van Hullebusch, E. D.; Oturan, N.; Guibaud, G.; Esposito, G.; Oturan, M. A. Impact of Electrochemical Treatment of Soil Washing Solution on PAH Degradation Efficiency and Soil Respirometry. Environ. Pollut. 2016, 211, 354362.

(77) Huguenot, D.; Mousset, E.; van Hullebusch, E. D.; Oturan, M. A. Combination of Surfactant Enhanced Soil Washing and Electro-Fenton Process for the Treatment of Soils Contaminated by Petroleum Hydrocarbons. J. Environ. Manage. 2015, 153, 40-47. 
(78) Mousset, E.; Oturan, N.; van Hullebusch, E. D.; Guibaud, G.; Esposito, G.; Oturan, M. A. Influence of Solubilizing Agents (Cyclodextrin or Surfactant) on Phenanthrene Degradation by Electro-Fenton Process - Study of Soil Washing Recycling Possibilities and Environmental Impact. Water Res. 2014, 48 (1), 306-316.

(79) Mousset, E.; Oturan, N.; van Hullebusch, E. D.; Guibaud, G.; Esposito, G.; Oturan, M. A. Treatment of Synthetic Soil Washing Solutions Containing Phenanthrene and Cyclodextrin by Electro-Oxidation. Influence of Anode Materials on Toxicity Removal and Biodegradability Enhancement. Appl. Catal. B Environ. 2014, 160-161, 666-675.

(80) Mousset, E.; Wang, Z.; Lefebvre, O. Electro-Fenton for Control and Removal of Micropollutants - Process Optimization and Energy Efficiency. Water Sci. Technol. 2016, 74 (2), 2068-2074.

(81) Oturan, N.; Brillas, E.; Oturan, M. A. Unprecedented Total Mineralization of Atrazine and Cyanuric Acid by Anodic Oxidation and Electro-Fenton with a Boron-Doped Diamond Anode. Environ. Chem. Lett. 2012, 10 (2), 165-170.

(82) Trellu, C.; Péchaud, Y.; Oturan, N.; Mousset, E.; Huguenot, D.; van Hullebusch, E. D.; Esposito, G.; Oturan, M. A. Comparative Study on the Removal of Humic Acids from Drinking Water by Anodic Oxidation and Electro-Fenton Processes: Mineralization Efficiency and Modelling. Appl. Catal. B Environ. 2016, 194, 32-41.

(83) Miao, J.; Zhu, H.; Tang, Y.; Chen, Y.; Wan, P. Graphite Felt Electrochemically Modified in $\mathrm{H} 2 \mathrm{SO} 4$ Solution Used as a Cathode to Produce $\mathrm{H}_{2} \mathrm{O}_{2}$ for Pre-Oxidation of Drinking Water. Chem. Eng. J. 2014, 250, 312-318.

(84) Yu, F.; Zhou, M.; Yu, X. Cost-Effective Electro-Fenton Using Modified Graphite Felt That Dramatically Enhanced on $\mathrm{H}_{2} \mathrm{O}_{2}$ Electro-Generation without External Aeration. Electrochim. Acta 2015, 163, 182-189.

(85) Assumpção, M. H. M. T.; Moraes, a.; De Souza, R. F. B.; Gaubeur, I.; Oliveira, R. T. S.; Antonin, V. S.; Malpass, G. R. P.; Rocha, R. S.; Calegaro, M. L.; Lanza, M. R. V.; et al. Low Content Cerium Oxide Nanoparticles on Carbon for Hydrogen Peroxide Electrosynthesis. Appl. Catal. A Gen. 2012, 411-412, 1-6.

(86) Zhang, G.; Yang, F.; Gao, M.; Fang, X.; Liu, L. Electro-Fenton Degradation of Azo Dye Using Polypyrrole/anthraquinonedisulphonate Composite Film Modified Graphite Cathode in Acidic Aqueous Solutions. Electrochim. Acta 2008, 53 (16), 5155-5161.

(87) Wang, Z. X.; Li, G.; Yang, F.; Chen, Y. L.; Gao, P. Electro-Fenton Degradation of Cellulose Using graphite/PTFE Electrodes Modified by 2-Ethylanthraquinone. Carbohydr. Polym. 2011, 86 (4), 1807-1813.

(88) Zhang, G.; Zhou, Y.; Yang, F. FeOOH-Catalyzed Heterogeneous Electro-Fenton System upon Anthraquinone @ Graphene Nanohybrid Cathode in a Divided Electrolytic Cell : Catholyte-Regulated Catalytic Oxidation Performance and Mechanism. J. Electrochem. Soc. 2015, 162 (6), H357-H365.

(89) Mousset, E.; Frunzo, L.; Esposito, G.; van Hullebusch, E. D.; Oturan, N.; Oturan, M. A. A Complete Phenol Oxidation Pathway Obtained during Electro-Fenton Treatment and Validated by a Kinetic Model Study. Appl. Catal. B Environ. 2016, 180, 189-198.

(90) Pimentel, M.; Oturan, N.; Dezotti, M.; Oturan, M. A. Phenol Degradation by Advanced Electrochemical Oxidation Process Electro-Fenton Using a Carbon Felt Cathode. Appl. Catal. B Environ. 2008, 83 (1-2), 140-149.

(91) Oturan, M. A.; Pimentel, M.; Oturan, N.; Sirés, I. Reaction Sequence for the Mineralization of the Short-Chain Carboxylic Acids Usually Formed upon Cleavage of Aromatics during Electrochemical Fenton Treatment. Electrochim. Acta 2008, 54 (2), $173-182$. 